\title{
Editorial
}

doi: $10.35366 / 99129$

\section{Cómo hemos crecido}

\section{How we've grown up}

\author{
Encalada-Díaz MI*
}

Growing up is hard, otherwise everyone would do it. Kim Harrison

Cerramos el 2020, año extraordinario por muchas razones y en el ámbito científico también se encontraron cambios y variantes de la publicación. La crisis global del coronavirus está planteando grandes cambios sociales, políticos y económicos que ya están teniendo consecuencias en el día a día, transformando usos y costumbres para luchar contra la enfermedad. En nuestra revista Acta Ortopédica Mexicana también notamos el impacto, se generó un número con trabajos específicos acerca del coronavirus buscando abrir un foro de discusión en el campo de nuestra especialidad.

En este año se mantuvo la recepción de trabajos de investigación e incluso esta publicación se vio incrementado por segundo año consecutivo, notando mayor participación de autores nacionales y extranjeros; este incremento nos ha llevado a promover la actualización de un gestor de trabajos en línea para que en el primer semestre del 2021 revisen nuestras nuevas pautas para los autores, esperamos que la aplicación de la tecnología mejore la dinámica de flujo de los trabajos enviados.

Uno de los cambios programados para el año 2021 será que los reportes de caso desaparecerán de la versión impresa de la revista para promover más el envío de trabajos originales, así como su futura publicación.

En esta ocasión, les mostraremos revisiones epidemiológicas de la incidencia de fracturas y de la lumbalgia, permitiendo cierto nivel de comparación, así como revisar las diferencias de enfoque entre los sistemas de salud. Se muestra la experiencia mixta de un grupo de investigadores sobre artroscopía de tobillo, región en donde aún hay un campo extenso para desarrollar. Contamos con un trabajo en inglés por nuestros autores mexicanos que esperemos mejore nuestra proyección en el ámbito mundial. Los trabajos de revisión en esta ocasión muestran aspectos relevantes de las lesiones de columna, las fracturas de radio distal y la controvertida «hiperlaxitud».

Espero disfruten este número y que para el 2021 sigamos contando con su preferencia para el envío de trabajos originales.

\section{wwW.medigraphic.org.mx}

\footnotetext{
* Editor en Jefe, Acta Ortopédica Mexicana. México.
}

Correspondencia:

Melchor Iván Encalada-Díaz

E-mail: encaladaiv@yahoo.com 